\title{
Preparation and Characterization of KOH-Activated Carbons Developed from Petroleum Coke
}

\author{
S. A. Sayed Ahmed`, Reham M. M. Abo El-enin and Th. El-Nabarawy \\ Department of physical Chemistry, National Research Centre, Dokki, Cairo, Egypt \\ ‘e-mail: sohairabdelaziz@yahoo.com \\ (Received September 1, 2009; Accepted November 21, 2009)
}

\begin{abstract}
Potassium hydroxide activated carbons were prepared from Egyptian petroleum cokes with different $\mathrm{KOH} / \mathrm{coke}$ ratios and at different activation temperatures and times. The textural properties were determined by adsorption of nitrogen at $-196^{\circ} \mathrm{C}$. The adsorption of iodine and methylene blue was also investigated at $30^{\circ} \mathrm{C}$. The surface area and the non-micropore volume increased whereas the micropore volume decreased with the increase of the ratio $\mathrm{KOH} / \mathrm{coke}$. Also the surface area and porosity increased with the rise of activation temperature from 500 to $800^{\circ} \mathrm{C}$. Textural parameter considerably increased with the increase of activation time from 1 to $3 \mathrm{~h}$. Further increasing of activation time from 3 to $4 \mathrm{~h}$ was associated with a less pronounced increase in textural parameters. The adsorption of iodine shows the same trend of surface area and porosity change exhibited by nitrogen adsorption, with $\mathrm{KOH} /$ coke ratio and temperature of activation. Adsorption of methylene blue follows pseudo-first-order kinetics and its equilibrium adsorption follows Langmuir and D-R models.
\end{abstract}

Keywords : KOH/coke, Preparation, Characterization, Nitrogen, Methylene blue, Iodine adsorption

\section{Introduction}

Activated carbons with expanded surface area and large pore volume are widely used as versatile adsorbents for the adsorption of gaseous and liquid phases. Activated carbons can be produced from a variety of raw materials of these, agricultural wastes, coal, petroleum cokes are the most commonly used precursors.

Cokes are byproducts of the petroleum industry. With their use as activated carbon, a high added value can be obtained. Petroleum coke is a good precursor for preparing high surface area active carbons [1-7].

Basically, the methods for preparation of active carbons can be grouped into two types, physical activation method and the chemical activation methods [2]. In the case of the chemical method, the commonly used activating agents include $\mathrm{KOH}, \mathrm{ZnCl}_{2}, \mathrm{H}_{3} \mathrm{PO}_{4}, \mathrm{H}_{2} \mathrm{SO}_{4}$, etc. Ahmadpour and Do [8] reported that the most important parameter in chemical activation with $\mathrm{KOH}$ is the extent of alkali impregnation and that chemical activation is more flexible in producing more varieties of activated carbons with desirable pore size distributions [9]. No general mechanism for chemical activation has been adopted [10]. However, it is now well established that the nature of the raw material, the type and amount of activating agent, the process of activation involved and the operative parameters in this process play important roles in determining the textural properties and consequently the adsorption capacity of activated carbon obtained [11-18].

The textural properties of adsorbents are conventionally determined from nitrogen adsorption at $-196^{\circ} \mathrm{C}$. However, more information could be obtained by determining the adsorption isotherms from the liquid phase, e.g. by comparing the adsorption of fairly large molecules of methyl blue or iodine.

The present investigation is devoted to prepare chemically activated carbons from a cheap and abundant precursor. Petroleum coke from El-Nasr Company (Suez- Egypt) is a byproduct and its accumulation represents a problem to the company. Potassium hydroxide was selected as an activating agent that can be regenerated for further activation cycles [19]. The determination of the textural properties of the activated carbons prepared via nitrogen adsorption is one of the objects of this investigation. The adsorption of iodine from aqueous potassium iodide at different temperature and also the adsorption of methylene blue dye from aqueous solution have been investigated and the results were discussed to show the role of some textural parameters and conditions of activation in determining the sorption capacity of the activated carbons prepared.

\section{Experimental}

\subsection{Materials}

A typical Egyptian petroleum coke from El-Nasr Co. 
Table 1. Elemental analysis of petroleum coke

\begin{tabular}{cccccc}
\hline Sample & \multicolumn{5}{c}{ Elemental analysis (wt \%) } \\
\cline { 2 - 6 } & $\mathrm{C}$ & $\mathrm{H}$ & $\mathrm{S}$ & $\mathrm{N}$ & $\mathrm{O}^{\mathrm{a})}$ \\
\hline Petroleum coke & 83.62 & 3.70 & 4.35 & 1.07 & 2.26 \\
\hline
\end{tabular}

a) by difference

(Suez-Egypt) was used as a precursor for the preparation of activated carbons. It was ground, sieved and the grain size in the range $125 \sim 210 \mu \mathrm{m}$ was selected. The sample was dried at $110^{\circ} \mathrm{C}$ till constant weight. The elemental analysis of the raw material was made using Vario El-Elementar instrument at National Research Centre. The data of elemental analysis is listed in Table 1.

\subsection{Preparation of activated carbons}

Chemical activation with $\mathrm{KOH}$ was carried out using the impregnation method. Thus $10 \mathrm{~g}$ of coke were mixed by stirring with $50 \mathrm{ml}$ of aqueous solutions containing, different weights of $\mathrm{KOH}$ according to the $\mathrm{KOH} /$ coke ratio required. The mixture was equilibrated at room temperature for 3 days, dried at $120^{\circ} \mathrm{C}$ before carbonization in nitrogen atmosphere. The rate of heating was $10^{\circ} \mathrm{C} / \mathrm{min}$ and the sample was soaked at the maximum temperature required for $1 \sim 4 \mathrm{~h}$. Details of preparation and activation are given elsewhere [19]. The activated carbons were designated as follows: the letter prefers to carbons impregnated with 10, 20 and $40 \mathrm{~g}$, respectively. The letters a, b, c and d following the Arabic number, indicate the activation time 1, 2, 3 and $4 \mathrm{~h}$, respectively. The last Arabic number in each designation gives when multiplied by 100 , the activation temperature. Thus for example, the designation P2c7 stands for the activation carbon prepared by impregnating the coke with $\mathrm{KOH}$ at a ratio of $\mathrm{KOH} /$ coke $=2$ and carbonized for $3 \mathrm{~h}$ at $700^{\circ} \mathrm{C}$ whereas for $\mathrm{P} 4 \mathrm{a} 8, \mathrm{KOH} /$ coke ratio $=4$, the time of activation was $1 \mathrm{~h}$ and the activation temperature was $800^{\circ} \mathrm{C}$.

\subsection{Characterization of activated carbons}

The activated carbons were characterized via measurements of the Brunauer-Emmett-Teller (BET) surface area, iodine number and methylene blue dye adsorption. The BET surface area was determined by nitrogen adsorption at $-196^{\circ} \mathrm{C}$ using a conventional volumetric apparatus. Prior to any adsorption measurement, the carbon sample was degassed at $200^{\circ} \mathrm{C}$ for $6 \mathrm{~h}$ under a reduced pressure at $10^{-5}$ torr. For the determination of iodine number, aqueous $\mathrm{I} / \mathrm{KI}$ solutions with an $\mathrm{I}_{2}$ concentration of $0.05 \mathrm{~mol} / \mathrm{L}$ were used in adsorption experiments. Activated carbon $(0.25 \mathrm{~g})$ was added in $50 \mathrm{ml}$ of this solution and shaken at $30^{\circ} \mathrm{C}$ for $24 \mathrm{~h}$ in the dark colored bottles. The residual concentration of $\mathrm{I}_{2}$ was determined by titration against $\mathrm{Na}_{2} \mathrm{~S}_{2} \mathrm{O}_{3}$ using the starch as indicator. The amount of $\mathrm{I}_{2}$ adsorbed was calculated from the difference between the amount of $\mathrm{I}_{2}$ in the initial solution and in the supernatant. Finally, the iodine number was calculated as the number of $\mathrm{mg}$ iodine adsorbed per $\mathrm{g}$ activated carbon.

Kinetics and equilibrium adsorption of methylene blue (MB) was investigated at $30^{\circ} \mathrm{C}$. For kinetic measurement, the initial concentration of $\mathrm{MB}$ was $(100 \mathrm{mg} / \mathrm{l})$ used and equilibrium time of $10 \sim 1500 \mathrm{~min}$ was allowed. The equilibrium adsorption of $\mathrm{MB}$ was performed using different initial concentration of $\mathrm{MB}$ and an equilibrium time of $24 \mathrm{~h}$ was allowed. The residual concentrations of $\mathrm{MB}$ were measured using UV-visible spectrophotometer at $\lambda_{\max }=626 \mathrm{~nm}$. All the experiments were carried out in duplicate and the average values were considered.

\section{Results and Discussions}

The textural properties of an adsorbent determine its adsorption capacity and adsorption selectivity. These textural properties are conventionally determined from the data of nitrogen adsorption of the adsorbent at $-196^{\circ} \mathrm{C}$. For all the activated carbons prepared in this investigation, the adsorption-desorption isotherms were made at $-196^{\circ} \mathrm{C}$. The adsorption was followed until near saturation, i.e, at a relative vapor pressure approaching unity $\left(\mathrm{p} / \mathrm{p}^{\circ} \approx 1.0\right)$ and the desorption branch was followed until the closure of the hysteresis loop was observed.

The nitrogen adsorption data were carefully analyzed using the conventional BET method [20] for the determination of the specific surface area $S_{B E T}\left(\mathrm{~m}^{2} / \mathrm{g}\right)$, the total pore volume $V_{T}(\mathrm{ml} / \mathrm{g})$ and the mean pore radius $\bar{r}$ (nm). The $\alpha$-method [21] was also used to determine two other important textural parameters, namely the micropore volume $v_{m}^{a}(\mathrm{ml} / \mathrm{g})$ and the non-micropore volume $v_{m}^{a}(\mathrm{ml} / \mathrm{g})$.

The most important factors contributing to the textural properties of chemically activated carbons are: the type of precursor [6,22] and the type of activating agent [21,23]. However, many other operational conditions affect the textural characteristics. These conditions include: pretreatment of the precursor before activation [24], procedure of activation [1], atmosphere of carbonization and/or activation, rate of heating during carbonization and /or activation, activation temperature $[3,12]$ activation time $[1,22]$ and the activating agent/ precursor weight ratio [22-25]. The last three operational conditions were selected in the present investigation.

\subsection{Effect of activating agent/precursor weight ratio}

Three samples with activating agent/ precursor ratios of 1, 2 and 4 (P1c7, P2Xc7, and P4c7) were prepared according to the procedure given in details in the experiment part of this paper.

The nitrogen adsorption isotherms of these carbons are shown in Fig. 1. It is depicted that the isotherms of P1c7 and 


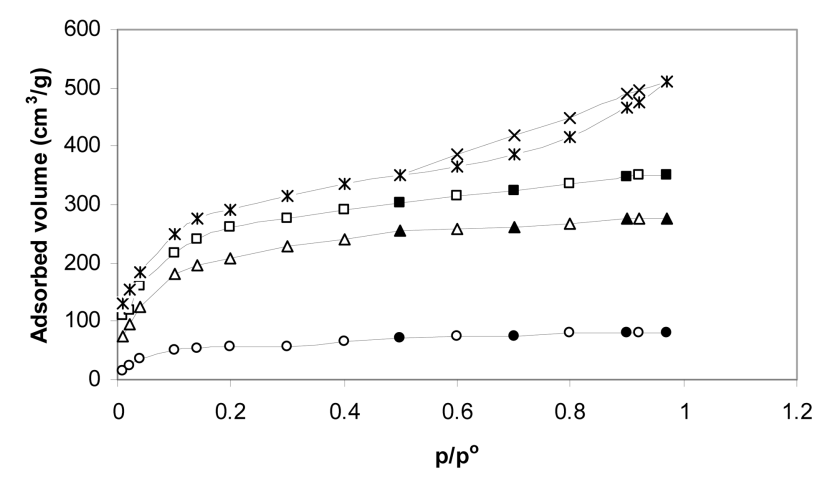

Fig. 1. Influence of the impregnation ratio, $R$, on the nitrogen adsorption isotherm of the resulting activated carbon. Data points relate to the following $\mathrm{R}$ values: $\bigcirc, 0 ; \Delta, 1.0 ; \square, 2.0 ; \times$, 4.0.

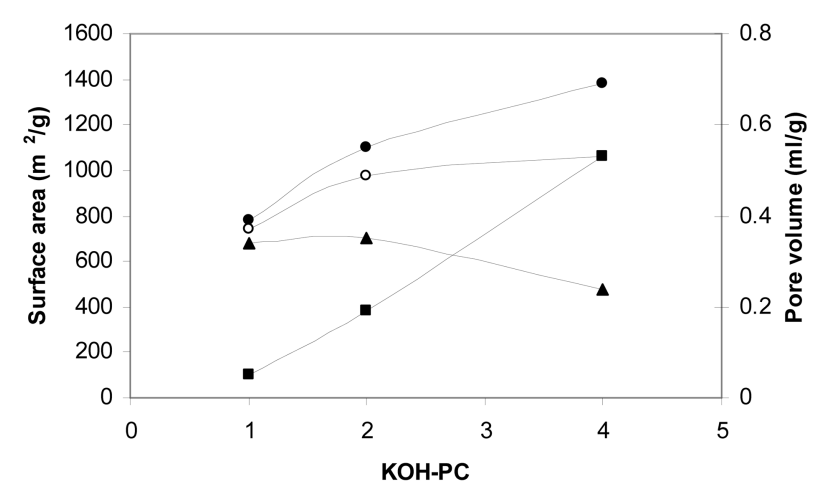

Fig. 2. Influence of the impregnation ratio, $\mathrm{R}$, on the specific surface area, on the pore volumes of the resulting activated carbon. Experimental conditions employed temperature $=750^{\circ} \mathrm{C}$; activation time $=3 \mathrm{~h} ; \mathrm{R}=4.0 ; \bigcirc$, surface area; $\boldsymbol{\Delta}$, micropores; $\mathbf{\square}$, non-micropores; $\boldsymbol{\bullet}$, total pore volume.

P2c7 are typical type I characteristic of adsorption in micropores [26]. The nitrogen adsorption isotherm of $\mathrm{P} 4 \mathrm{c} 7$ is quite different than those of the other two carbons. Thus, although it is mostly of type I, it shows upward deviation above $\mathrm{P} / \mathrm{P}^{\mathrm{0}}=0.5$ and also exhibits closed hysteresis loop. This upward deviation together with the existence of hysteresis loop indicates the tendency of the adsorption isotherm to show some characteristics of type IV.

The effect of activating agent/ precursor weight ratio could be clearly observed in Fig. 2. Fig. 2 depicts that $S_{B E T}$ increased with the increase of the ratio. However, the increase of $S_{B E T}$ is more pronounced with the increase of the ratio from 1 to 2 . This may at least be partially attributed to the associated changes in the pore dimensions. The change of pore dimensions with the change of the activating agent/ precursor ratio is also shown in Fig. 2. Thus, the micropore volume continuously decreased whereas the non-micropore volume increased with the increase of the ratio from 1 to 4 . During chemical activation with $\mathrm{KOH}$, the mechanism of pore formation may involve (i) creation of micropores due to

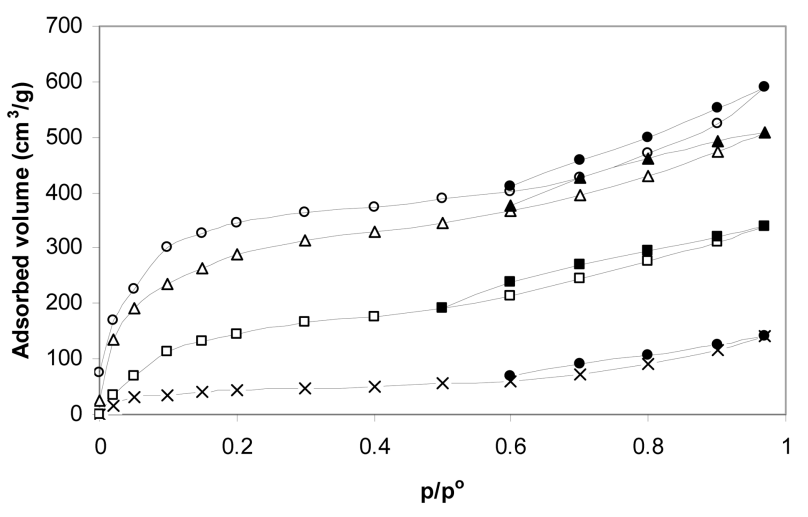

Fig. 3. Influence of activation temperature on the nitrogen adsorption isotherm of the resulting activated carbon. Data points related to the following activation temperature, $\times, \mathrm{P} 4 \mathrm{c} 5$; $\square, \mathrm{P} 4 \mathrm{c} 6 ; \Delta, \mathrm{P} 4 \mathrm{c} 7 ; \bigcirc, \mathrm{P} 4 \mathrm{c} 8$.

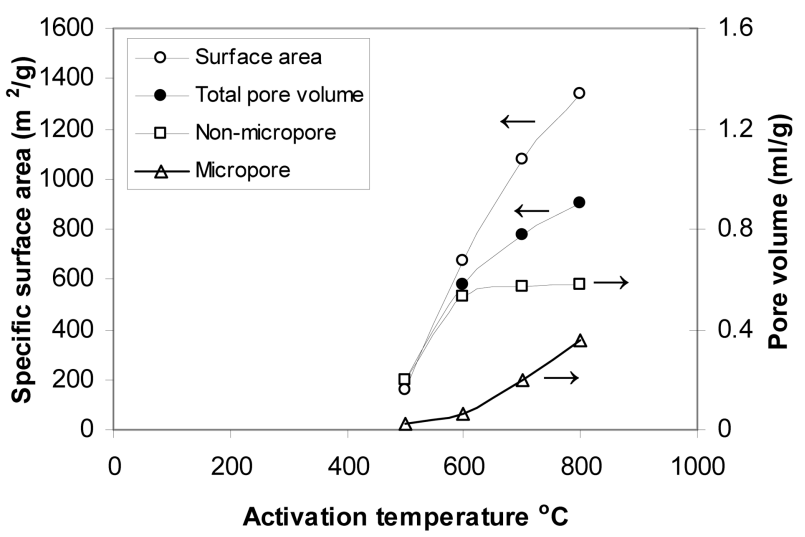

Fig. 4. Influence of activation temperature on the specific surface area and pore volumes of the resulting activated carbon. Experimental conditions employed $\mathrm{R}=4.0$; activation time $=3 \mathrm{~h}$.

the evolution of gaseous products such as $\mathrm{H}_{2}, \mathrm{CH}_{4}, \mathrm{CO}$ and $\mathrm{CO}_{2}$. (ii) removal of the corresponding metal salts from the internal volume of the carbon during the washing step. (iii) with the increase of $\mathrm{KOH} /$ coke ratio, the amounts of $\mathrm{CO}_{2}$ and water vapor increase. These oxidizing gases cause errosion of pore walls leading thus to pore widening.

\subsection{Effect of the activation temperature}

Four KOH-activated carbons containing the same amount of the activating agent were prepared by carbonization at $500,600,700$ and $800^{\circ} \mathrm{C}$. The activated carbons thus obtained were designated $\mathrm{P} 4 \mathrm{c} 5, \mathrm{P} 4 \mathrm{c} 6, \mathrm{P} 4 \mathrm{c} 7$ and $\mathrm{P} 4 \mathrm{c} 8$. Fig. 3 shows the nitrogen adsorption-desorption isotherms. They are all of almost type I isotherms but with a tendency to show characteristics of type IV at $\mathrm{p} / \mathrm{p}^{0} \geq 0.5$. Also the isotherms show hysteresis loop above this relative pressure with the area of the hysteresis loop increasing with the rise of the activation temperature. The changes in the textural properties with the change of activation with $\mathrm{KOH}$ are 
Table 2. Textural properties of P4a7, P4b7, P4c7 and P4d7

\begin{tabular}{cccccc}
\hline Sample & $\begin{array}{c}S_{B E T} \\
\left(\mathrm{~m}^{2} / \mathrm{g}\right)\end{array}$ & $\begin{array}{c}V_{T} \\
\mathrm{ml} / \mathrm{g}\end{array}$ & $\begin{array}{c}r \\
(\mathrm{~nm})\end{array}$ & $\begin{array}{c}v_{m}^{a} \\
\mathrm{ml} / \mathrm{g}\end{array}$ & $\begin{array}{c}v_{n}^{a} \\
\mathrm{ml} / \mathrm{g}\end{array}$ \\
\hline $\mathrm{P} 4 \mathrm{a} 7$ & 650 & 0.433 & 1.36 & 0.199 & 0.244 \\
\hline $\mathrm{P} 4 \mathrm{~b} 7$ & 930 & 0.667 & 1.40 & 0.204 & 0.463 \\
\hline $\mathrm{P} 4 \mathrm{c} 7$ & 1042 & 0.775 & 1.47 & 0.248 & 0.527 \\
\hline $\mathrm{P} 4 \mathrm{~d} 7$ & 1062 & 0.785 & 1.48 & 0.256 & 0.529 \\
\hline
\end{tabular}

depicted in Fig. 4. It is shown that $\mathrm{S}_{\mathrm{BET}}$ increases linearly with the increase of the activation temperature. This means that $\mathrm{KOH}$ activation is recommended at temperature as high as $800^{\circ} \mathrm{C}$. This is in a good agreement with previously reported data [3]. The micropore volume of $\mathrm{P} 4 \mathrm{c} 5$ represents only about $11 \%$ of the total pore volume of the sample. For $\mathrm{P} 4 \mathrm{C} 6, v_{m}^{a}$ equal about $14 \%$ of $\mathrm{V}_{\mathrm{T}}$. The contribution of micropores to the total pore volume is more pronounced for $700^{\circ} \mathrm{C}$ and further at $800^{\circ} \mathrm{C}$. Thus for $\mathrm{P} 4 \mathrm{c} 7, v_{m}^{a} / \mathrm{V}_{\mathrm{T}}=31 \%$ and for $\mathrm{P} 4 \mathrm{c} 8, v_{m}^{a} / \mathrm{V}_{\mathrm{T}}=38 \%$.

At $500^{\circ} \mathrm{C}$, some evolved lower hydrocarbons may be trapped within the micropores and may condense during cooling closing thus a fraction of these micropores. The rise of the activation temperature enhances the evolution and diffusion of gaseous carbonaceous products leaving behind well developed microporous structure.

\subsection{Effect of activation time}

Chemical activation involves carbonization of impregnating the raw carbonaceous material with the activating agent at a certain carbonization temperature. In the course of carbonization the impregnated raw material is heated from room temperature at a heating rate usually $10^{\circ} \mathrm{C} / \mathrm{min}$ to reach the carbonization at which the material is soaked for a certain time known as the activation time.

In the present investigation samples of $\mathrm{KOH} /$ Petroleum coke weight ratio $=4$ were soaked at $700^{\circ} \mathrm{C}$ for $1,2,3$ and $4 \mathrm{~h}$ to give samples $\mathrm{P} 4 \mathrm{a} 7, \mathrm{P} 4 \mathrm{~b} 7, \mathrm{P} 4 \mathrm{c} 7$, and $\mathrm{P} 4 \mathrm{~d} 7$ respectively.
The textural properties of these samples as determined from their nitrogen adsorption data are listed in Table 2.

Table 2 reveals that increasing the activation time from one hour to four hours is always associated by an increase in all the textural parameters, i.e increase in the $S_{B E T}, \mathrm{~V}_{\mathrm{T}}, v_{m}^{a}$, $v_{n}^{a}$, and $\bar{r}$. However, the increase in the textural parameters is more pronounced upon increasing the activation time from 1 to $2 \mathrm{~h}$, the increase in the textural parameter with the further increase of activation time from 2 to $3 \mathrm{~h}$ is less pronounced. Negligible increase in all textural parameter is noticed when the activation time increases from 3 to $4 \mathrm{~h}$. For example an increase of $S_{B E T}$ of about $43 \%$ with the increase of activation time from 1 to $2 \mathrm{~h}$, the increase of $S_{B E T}$ with the increase of activation time from 2 to $3 \mathrm{~h}$ amounts only to about $12 \%$. Only an increase of $1.9 \%$ was determined upon increasing the activation time from 3 to $4 \mathrm{~h}$. The increase of the values of the other textural parameters seems to be less pronounced. This indicates that activation for $3 \mathrm{~h}$ is quite sufficient to remove completely the volatile matter and the removal of the corresponding salts from the internal volume of the activated carbon.

Based on these results one can suggest that soaking the $\mathrm{KOH}$ - impregnated carbonaceous precursor at $700 \sim 800^{\circ} \mathrm{C}$ for $3 \mathrm{~h}$ is quite sufficient to produce highly activated carbons with expanded surface area and well developed pore structure.

\subsection{Adsorption of iodine from aqueous KI solution}

The maximum sorption capacity of activated carbons from solutions is very important because it determines its practical applications in many industrial and environmental sectors. The adsorption of iodine from aqueous solution by an activated carbon may be considered as criterion to its potential for the adsorption from solution.

In the present investigation, the adsorption of iodine at $30^{\circ} \mathrm{C}$ was followed on $\mathrm{P} 4 \mathrm{c} 5, \mathrm{P} 4 \mathrm{c} 6, \mathrm{P} 4 \mathrm{c} 7$ to determine the effect of activation temperature and on $\mathrm{P} 1 \mathrm{c} 7, \mathrm{P} 2 \mathrm{c} 7$, and $\mathrm{P} 4 \mathrm{c} 7$
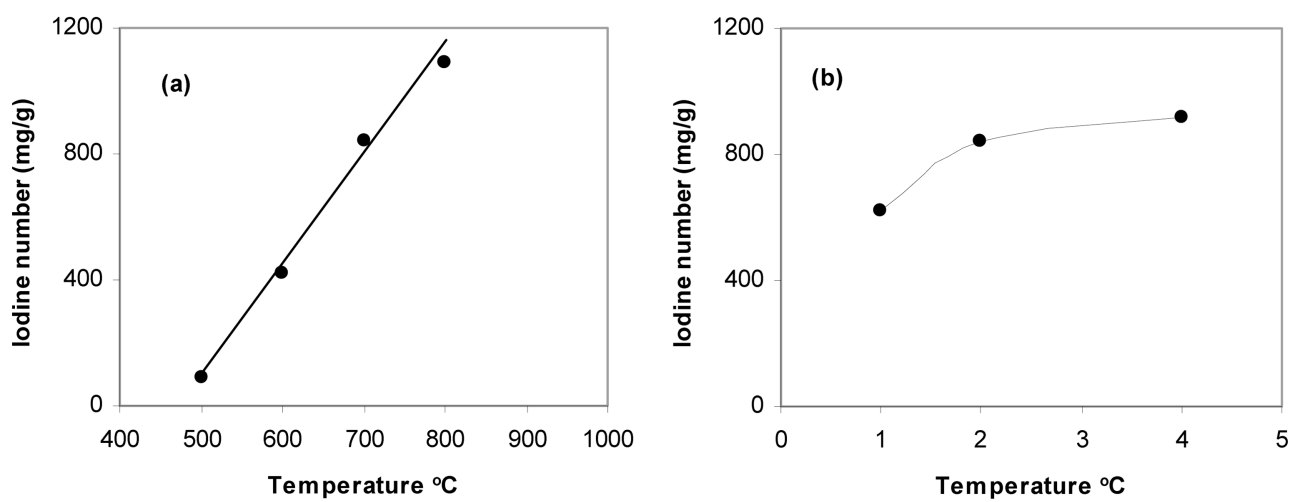

Fig. 5. (a) Influence of activation temperature on the iodine number. Experimental conditions employed $\mathrm{R}=4.0$, activation temperature $=3 \mathrm{~h}$. (b) Influence of activation temperature on the iodine number. Experimental temperature $=700^{\circ} \mathrm{C}$, activation time $=3 \mathrm{~h}$ 


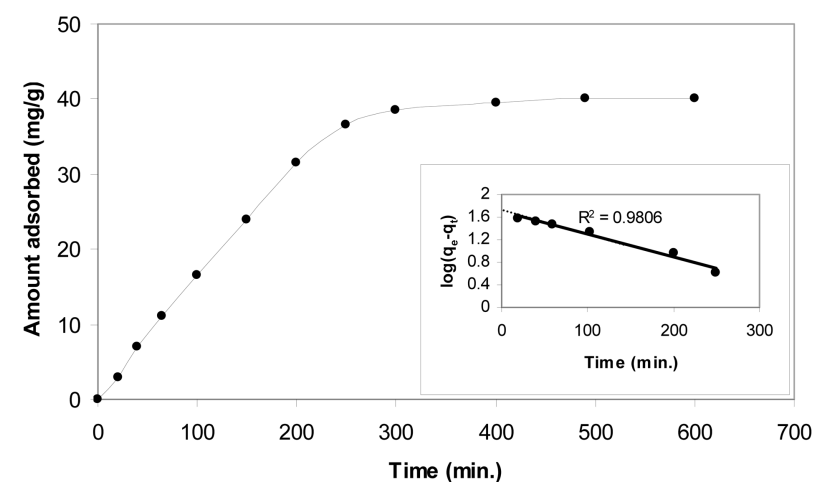

Fig. 6. Kinetic curve for the adsorption of methylene blue onto the activated carbon $\mathrm{P} 4 \mathrm{c} 7$ at $30^{\circ} \mathrm{C}$. The inset shows the applicability of the pseudo- first order model to the experimental data.

to determine the effect of the amount of the activating agent.

Fig. 5a shows the effect of activation temperature on iodine sorption capacity expressed as iodine number $(\mathrm{mg} / \mathrm{g})$ and Fig. 5b shows the effect of $\mathrm{KOH} /$ petroleum coke weight ratio. Fig. 5a shows a satisfactory linear relationship between the iodine number and the activation temperature. It has been previously mentioned in this paper that the rise of the activation temperature from 500 to $800^{\circ} \mathrm{C}$ is always associated with a continuous increase in all the textural properties. This may indicate that the changes in the textural properties in general and surface area in particular of activated carbons could be followed from the changes of their capacity towards iodine adsorption. Fig. 5b shows also that the iodine adsorption capacity increases with the increase of $\mathrm{KOH} /$ coke ratio, i.e. the same trend observed with the change in $S_{B E T}$ values measured by nitrogen adsorption. To summarize one can suggest that iodine sorption besides measuring the capacity of activated carbons for sorption from solution; it can also be used as a criterion for textural characterization of these carbons.

\subsection{Methylene blue adsorption}

The adsorption from solution depends to great extent on the time of equilibration between the solid sorbent and the solution. For this reason the determination of the equilibrium time for the adsorption from solution is of prime importance. The kinetics of adsorption allows the construction of a kinetic curve which shows the variation of the amount of the adsorbate uptake with time. The equilibrium time is expected to be at or after the plateau exhibited by the kinetic curve.

\subsubsection{Kinetics of methylene blue adsorption}

Fig. 6 shows the kinetic isotherm of methylene blue onto P4c7. In the initial stages, i.e. up to an equilibration time $\leq 250 \mathrm{~min}$., a straight line passing through the origin is shown indicating thus that sorption of MB follows pseudo-

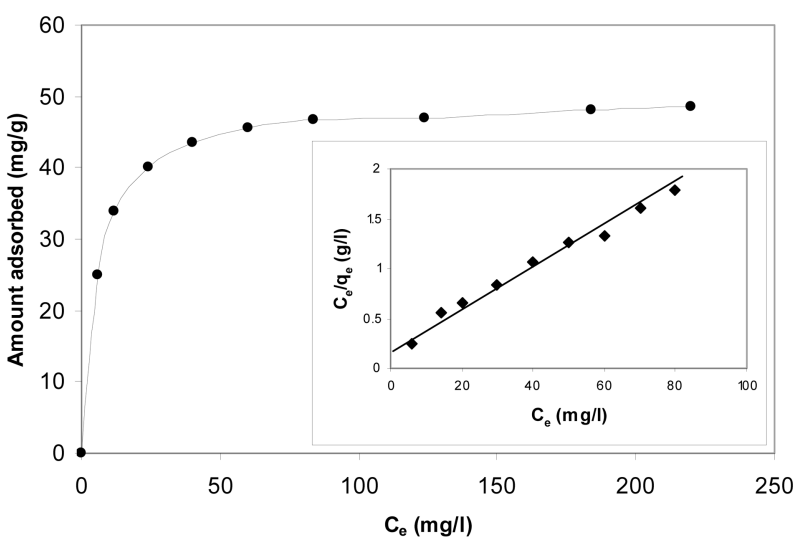

Fig. 7. Adsorption isotherm of methylene blue onto activated carbon $\mathrm{P} 4 \mathrm{c} 7$ at $30^{\circ} \mathrm{C}$. The inset shows the applicability of Langmuir isotherm to the experimental data.

first-order kinetics. Beyond equilibration time of $250 \mathrm{~min}$, a tendency to a plateau with a very small slope is exhibited. This plateau indicates that equilibrium adsorption of $\mathrm{MB}$ requires more than $4 \mathrm{~h}$ to be attained. However, in order to have equilibrium adsorption isotherms an equilibrium time of say $12 \mathrm{~h}$ should be allowed to ensure equilibrium conditions. The pseudo-first order kinetic equation:

$$
\log \left(q_{e}-q_{t}\right)=\log q_{e}-k_{l} t
$$

Where $q_{e}$ is the equilibrium adsorption capacity and $q_{t}$ is the amount adsorbed at time $t$ and $K_{l}$ is the adsorption rate constant $\left(\mathrm{min}^{-1}\right)$. Evidently, the value of $q_{e}$ read from the intercept to be $43.65 \mathrm{mg} / \mathrm{g}$ and the value of $K_{l}$ as determined from the slope of the straight line was calculated to be $2.5 \times 10^{-3} \mathrm{~min}^{-1}$.

\subsubsection{Equilibrium adsorption of methylene blue}

The equilibrium adsorption isotherm of methylene blue at $30^{\circ} \mathrm{C}$ onto $\mathrm{P} 4 \mathrm{c} 7$ is shown in Fig. 7. A contact time of $12 \mathrm{~h}$ was allowed to ensure equilibrium condition. The isotherm exhibits very initial steep portion followed by a plateau covering a wide range of equilibrium concentration. The Langmuir equation was applied to analyze the equilibrium adsorption data of MB onto P4c7. The inset of Fig. 7 shows the linear Langmuir plot of the isotherm. The data gave a good straight line with $\mathrm{R}^{2}=0.98$. The maximum adsorption capacity $q_{\max }$ was calculated to be $53.03 \mathrm{mg} / \mathrm{g}$ and Langmuir constant B was determined to be $0.067(1 / \mathrm{mg})$.

Another independent model was also applied to the equilibrium adsorption data of MB onto P4c7. This model adopted by Dubinin and Radushkevich (D-R) model [26] assumes that only a small fraction of the surface is uniform in structure and energetically homogeneous.

The D-R equation is given as

$$
q=q_{m} e^{-\beta \xi^{2}}
$$




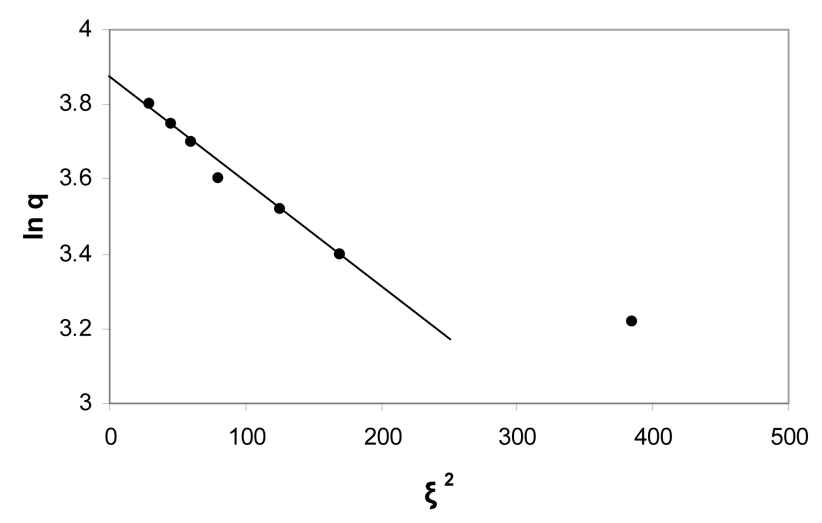

Fig. 8. Linear D-R plots of methylene blue sorption on activated carbon $\mathrm{P} 4 \mathrm{c} 7$.

where $\mathrm{q}$ is the amount adsorbed at the equilibrium concentration $\mathrm{C}_{\mathrm{e}}, q_{m}$, is the maximum amount adsorbed and can be called the adsorption capacity, $\beta$ is a constant related to the energy and $\xi$, the potential energy of the surface which equals $R T \ln \left(1+1 / C_{e}\right)$, where $\mathrm{R}$ is the gas constant $(\mathrm{kJ} / \mathrm{mol}$ $\mathrm{K}), \mathrm{T}$ is the absolute temperature. The $\mathrm{D}-\mathrm{R}$ equation can be written as

$$
\operatorname{In} q=\ln q_{m}-\beta \xi^{2}
$$

A plot of $\ln q$ versus $\xi$ gave a straight line as shown in Fig. 8. The values of $q_{m}$ and $\beta$ were obtained from the intercept and slope of the straight line to be $50.6 \mathrm{mg} / \mathrm{g}$ and $0.0025\left(\mathrm{~mol}^{2} / \mathrm{kJ}^{2}\right)$, respectively. The sorption energy $E_{a}(\mathrm{~kJ} /$ mol) can be obtained from the relationship

$$
E_{a}=1 / 2(-\beta)^{1 / 2}
$$

The calculated value of $E_{a}$ was $2.98 \mathrm{~kJ} \mathrm{~mol}^{-1}$. The $q_{m}$ value as determined from the D-R model is about $5 \%$ lower than that calculated from the Langmuir model. The $q_{m}$ determined from Langmuir model is always located at some point beyond the whole range of the adsorption isotherm, for this reason it is better called the maximum adsorption capacity $q_{m}$ from the Langmuir model may be considered as the monolayer capacity when the plateau of the isotherm does not exhibit any rising with the increase of the equilibrium concentration, the D-R model on the other hand, consider only sorption point of the isotherm preceding the plateau of the isotherm and therefore the $q_{m}$ determined from D-R model is of more significance [27]. The value of $E_{a}$ indicates that the adsorption of $\mathrm{MB}$ onto $\mathrm{KOH}$ - activated carbons is a physical type in which sorbent-sorbate interaction involves physical forces, i.e. dispersion or van der waal's forces.

\section{Conclusions}

I. The surface area and non-microporisty increased whereas the micropore volume decreased with the increased of $\mathrm{KOH} /$ coke ratio.

II. The increase of activation temperature increased the surface area and porosity. Activation for $3 \mathrm{~h}$ was quite sufficient to develop the texture of the $\mathrm{KOH}$-activated carbon.

III. The adsorption for iodine at 30C changes with $\mathrm{KOH} /$ coke ratio and activation temperature in a manner similar to that exhibited by nitrogen adsorption.

IV. Methylene blue adsorption follows pseudo-first-order kinetics and its equilibrium adsorption isotherms fitted both Langmuir and D-R models. The latter model allowed the determination of the activation energy of the adsorption.

\section{References}

[1] Mingho, W.; Qingfang, Z.; Jieshan, Q.; Xia H.; Yansheng G.; Zhaofeng, L.; Aijun, Y.; Xin S. Fuel 2005, 84, 1992.

[2] Si Hyun, L.; Cheong Song, C. Fuel Process. Technol. 2000, 64, 141.

[3] Takayuki, K.; Mitsuchiro, K.; Maurice, S.; Onyango, F. W.; Hitoki M. Appl. Therm. Eng. 2008, 28, 865.

[4] Tseng, R. L.; Tseng, S. K. J. Colloid Interface Sci. 2005, 287, 428.

[5] Stavropoulas, G. G.; Zabaniotou, A. A. Micropor Mesopor. Mater. 2005, 82, 79.

[6] Lillo-Rodenas, M. A.; Cazorla-Amoros, D.; Linares-Solano, A. Carbon 2003, 41, 267.

[7] Matani, S.; Lee, S. I.; Saito, K.; Yoon, S. H.; Korai, Y.; Mochida, I. Carbon 2005, 43, 2295.

[8] Ahmadpour, A.; Do, D. D. Carbon 1996, 34, 471.

[9] Ehrburger, P.; Addoun, A.; Addoun, F.; Ddonnet, J. B. Fuel 1986, 65, 1447.

[10] Lozono-Castello, D.; Lillo-Rodenas, M. A.; Cazorla-Amoros, D.; Linares-Rodenas, A. Carbon 2001, 39, 741.

[11] Yong, Z.; Bu-xing, H. Adsorp. Sci.; Technol. 2001, 19, 59.

[12] Mohammad, A.; Muhammed, A. R.; Mohammad, A. M.; Mohammad, B. S. Adsorp. Sci. \& Techol. 2006, 24, 761.

[13] Puziy, A. M.; Poddubnaya, 0. I.; Martinez-Alonso, A.; Suarez-Garcia, F.; Tascön, J. M. D. Carbon 2003, 41, 1181.

[14] Hayashi, J.; Uclübayashi, M.; Harikawa, T.; Muroyama, K.; Gomes, V. G. Carbon 2002, 40, 2747.

[15] Derpyshire, F.; Jagtoyen, M.; Thwaites, M. "Activated Carbons-Production; Application", in "Porosity in Carbon”, ed. J. W. Patrick, E. Amold, London, 1995, 228.

[16] Lua, A. C.; Yang, T.; Guo, J. J. Anal. Appl. Pyrolysis 2004, 72, 279.

[17] Phan, N. H.; Rio-S., F. C.; Le Cloirec, P.; Nguyen, T. H. Carbon 2006, 44, 2569.

[18] Tseng, R. L. J. Hazardous Materials 2007, 147, 1020.

[19] Fawzi, B.; Sameer, A.-A.; Leema, M. Adsorp. Sci. \& Technol 2003, 21, 597.

[20] Brunauer, S.; Deming, D. W.; Deming, L. S.; Teller, E. J. 
Am. Chem. Soc. 1940, 62, 1723.

[21] Sing, K. S. W. Chem. Ind. London, 1968, 1520.

[22] Huiping, Z.; Ying Y.; Lichun Y. Adsop. Sci.\& Technol. 2008, 26, 533.

[23] Azeuedo Diana, C. S.; Araiyo, J. C. S.; Moises, B.-N; Torres, B.; Jaguaribe, F.; Cavalante, L. Microp or Mesopor 2007, 100, 361.

[24] Park, S.-J.; Jung, W.-Y.; J. Colloid. Interf. Sci. 2002, 250, 93.
[25] Sing, K. S. W.; Everett, D. H.; Haul, R. A. W.; Moscou, L.; Pierotti, R. A.; Rouquerol, J.; Siemieniewska, T. Pure Appl. Chem. 1985, 57, 603.

[26] Dubinin, M. M.; Radushkevich, L. V. Proc. Acad. Sci. USSR, Phys. Cem. Sect. 1947, 55, 331.

[27] Youssef, A. M.; El-Nabarawy, Th.; Samra, S. E. Colloids and Surfaces. A: Physicochem. Eng.: Aspects 2004, 235, 153. 